\title{
Study on Precise Measurement of Shear Modulus of Polymer Grouting Materials Using Piezoceramic Bender Elements
}

\author{
Jia LI, Bo WANG, Jingwei ZHANG
}

\begin{abstract}
In this paper, piezoceramic bender elements technology is first used to test the dynamic shear modulus of polymer grouting materials. The test procedure is designed and the related mould is manufactured. The problems of influencing the precise measuring the transmitting time of shear wave are solved including system delay, excitation signal, frequency and the method of determining the transmitting time. Based on it, the influence on polymer dynamic shear modulus of density and excitation frequency is analyzed, the dynamic elastic modulus and static elastic modulus are contrasted and the relation of polymer grouting materials and dam construction materials is investigated. This study provides basic theoretical reference for dynamic response analysis and engineering application of polymer grouting materials.
\end{abstract}

Keywords: dynamic property; dynamic shear modulus; piezoceramic bender elements; polymer grouting materials

\section{INTRODUCTION}

China has the most number of reservoirs in the world. More than 87 thousand reservoirs have been constructed by the end of 2015. Most of the reservoirs are located in seismic regions and the seepage control system is usually the weakest part of the whole structure. Aiming at the need of reinforcement for dams and dikes, polymer anti-seepage wall has been developed by Zhengzhou University. The construction steps of this new-type impermeable and reinforced technology include pressing slots, casing slots, sealing slots and lifting grouting, which are shown in Fig. 1. Compared with traditional methods, the polymer grouting has the advantages of quick construction, light weight, good anti-permeability, material safety and environment friendly. Due to these advantages, the polymer anti-seepage wall has become the popular impermeable and reinforced method for Chinese mediumsize and small-size reservoirs. However, the dynamic properties of the dam with polymer anti-seepage wall have not been studied.

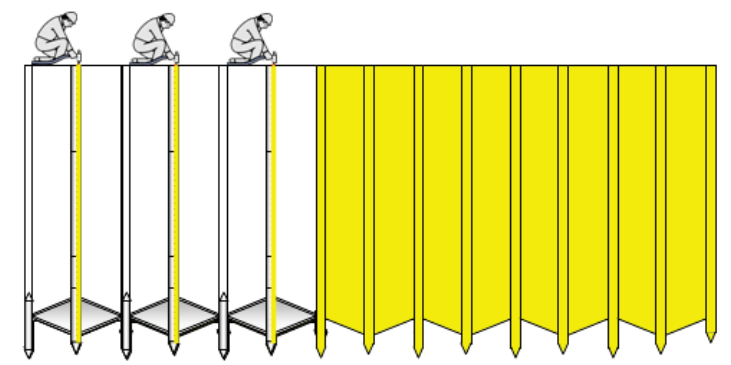

Figure1 The construction schematic diagram of polymer anti-seepage wall

Dynamic shear modulus of materials is an important parameter for dynamic analysis in geotechnical engineering. Piezoceramic bender elements were first introduced into the test of shear wave velocity for geotechnical materials by Shirley and Hampton [1]. Because of its clear principle, easy operation and damagefree testing characteristics, it has been widely used in the tests of small-strain shear modulus of soil samples. Ji Meixiu [2] researched how to precisely measure the shear wave velocity of soils with different type and rigidity; Wu Hongwei [3] studied the degree of inherent stiffness anisotropy of intact Shanghai soft clay using a triaxial apparatus equipped with Hall-effect local strain transducers and a bender element testing system. Zhou Yan-guo [4] investigated the characteristic of soil structure by shear wave velocity and evaluated the effects of soil structure on dynamic behavior via bender element testing. Gu Xiaoqiang [5] used bender element, resonant column and cyclic torsional shear to test the small strain shear modulus of dry sands. Bai Li-dong [6] studied contrast test on the maximum shear modulus of four kinds of dry sands obtained from Germany with the bender elements and resonant column. It can be seen the previous researches on applying bender elements are mainly focused on soft clay and sand. Study on two-component foaming polyurethane grouting materials by the bender elements is lacking. In consideration of no current specification for dynamic mechanic testing of polymer grouting materials and no experimental research references about its dynamic modulus and in view of its obvious elastic characteristics, the dynamic property of polymer grouting materials is studied by the bender elements in this paper.

In the paper piezoceramic bender elements system is first introduced in testing dynamic shear modulus $\left(G_{\max }\right)$ of polymer grouting materials. The testing program is designed and the testing mould is made. The influence of materials density and bender elements excitation frequency on dynamic shear modulus is researched. Dynamic modulus and static modulus are contrasted. The relationship of dynamic shear modulus of polymer antiseepage wall and dam construction materials is investigated.

\section{TEST PRINCIPLE}

Piezoceramic bender elements are composed of actuator and sensor. In the test the actuator and sensor are placed into materials. Shear wave is generated by function generator and actuator transversely vibrates by polarization of generated wave, which compels the material vibrating transversely. Sensor receives the vibration and converts it into electric signal, the transmitting signal and received signal are displayed on the screen of oscilloscope, and the shear wave velocity $v_{\mathrm{s}}$ is obtained via reading the 
transmitting time $t_{\mathrm{s}}$ of the signal wave. The equation is as follows [7]:

$v_{\mathrm{s}}=\frac{h}{t_{\mathrm{s}}}$

where, $h$ is the distance between the actuator port and the sensor port.

In the bender elements test, the materials change belongs to small deformation $\left(\gamma<10^{-6}\right)$, which is the ideal elastic deformation. Its dynamic shear modulus can be calculated according to elastic theory with known density $\rho$ :

$$
G_{\max }=\rho v_{\mathrm{s}}^{2}
$$

Influenced by materials damping, the transmitting velocity of shear wave in materials is not a constant but the maximum value near the bender elements. Therefore the test outcome is the small-strain maximum dynamic shear modulus, which is $G_{\max }$.

\section{TEST PLAN}

\subsection{The Mould for the Bender Elements Samples of Polymer Grouting Materials}

The polymer grouting materials are composed of twocomponent foaming polyurethane, with the characteristic of flowability and expansibility. Therefore specialized mould should be designed to mould the samples. In this test, a cylindrical mould and two pieces of steel plate are manufactured to mould the samples. The geometric dimensioning of the cylinder is $\varnothing 50 \times 150 \mathrm{~mm}$ and the schematic diagram is shown in Fig. 2. The steel plates are designed with circular slots which can be used to lock the cylinder. The steel plates are also designed with a little steel disc (10 $\mathrm{mm}$ wide, $2 \mathrm{~mm}$ thick) in the centre position to form the slot to place the actuator and sensor. The upper steel plate reserves grouting hole and is connected with the lower steel plate by stay bolts. The centre cylinder is designed to be two divided parts for demoulding. The specific mould is shown in Fig. 3.

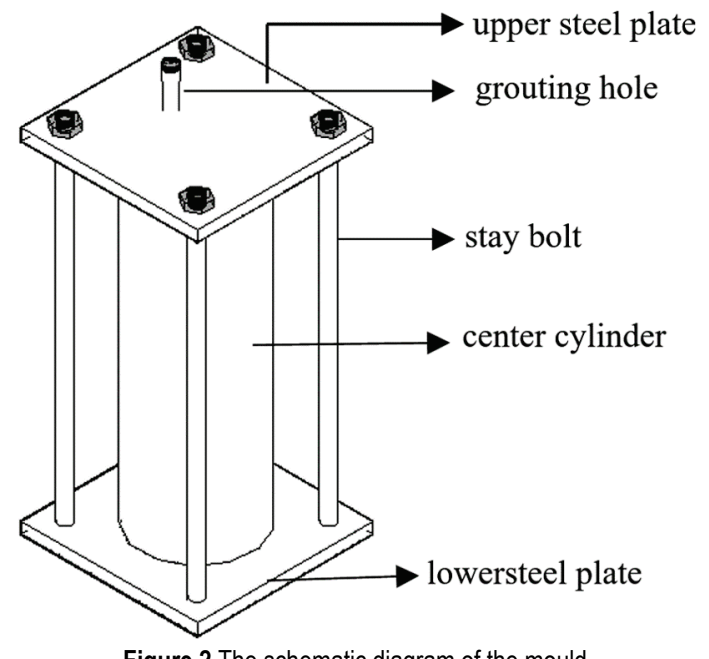

Figure 2 The schematic diagram of the mould
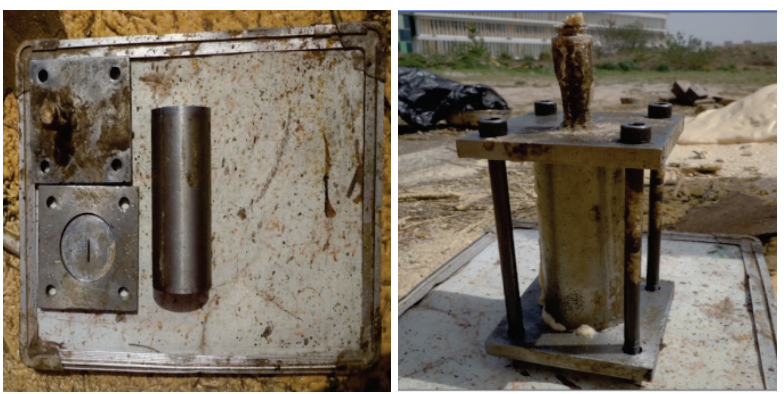

Figure 3 The specific mould of the bender elements samples

\subsection{The Bender Elements Samples of Polymer Grouting Materials}

In the test, the density of the materials is from 0.1 to $0.6 \mathrm{~g} / \mathrm{cm}^{3}$ with a changing step of $0.1 \mathrm{~g} / \mathrm{cm}^{3}$ and 5 sections are set. Detailed design number of samples is shown in Tab. 1.

Table 1 Design number of samples

\begin{tabular}{|c|c|}
\hline Density section $\left(\mathrm{g} / \mathrm{cm}^{3}\right)$ & Number of samples \\
\hline $0,1-0,2$ & $3-5$ \\
\hline $0,2-0,3$ & $3-5$ \\
\hline $0,3-0,4$ & $3-5$ \\
\hline $0,4-0,5$ & $3-5$ \\
\hline $0,5-0,6$ & $3-5$ \\
\hline Total & $15-25$ \\
\hline
\end{tabular}

The polymer grouting gun (Fig. 4) outpours about 125 $\mathrm{g}$ materials in every operation. Experienced technician can operate $1 / 2$ or $1 / 4$ shot dosage. The density of bender elements samples can be controlled by the number of the grouting shot. Grouting parameters of bender elements samples are shown in Tab. 2.

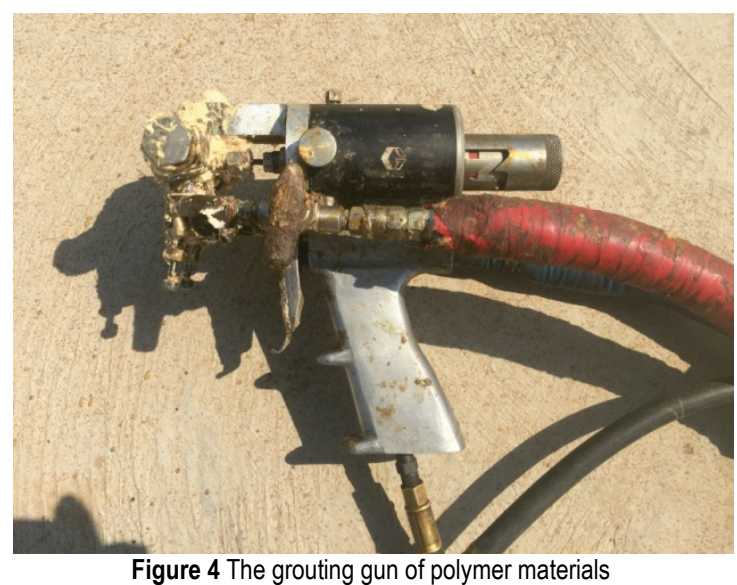

Table 2 Grouting parameters of bender elements samples

\begin{tabular}{|c|c|c|c|}
\hline $\begin{array}{c}\text { Density } \\
\left(\mathrm{g} / \mathrm{cm}^{3}\right)\end{array}$ & $\begin{array}{c}\text { Volume } \\
\left(\mathrm{cm}^{3}\right)\end{array}$ & $\begin{array}{c}\text { Weight } \\
(\mathrm{g})\end{array}$ & The number of the shot \\
\hline 0,1 & 294,375 & 29,500 & 0,236 \\
\hline $\mathbf{0 , 2}$ & $\mathbf{2 9 4 , 3 7 5}$ & $\mathbf{5 9 . 0 0 0}$ & $\mathbf{0 , 4 7 2}$ \\
\hline 0,3 & 294,375 & 88,500 & 0,708 \\
\hline 0,4 & 294,375 & 118.000 & 0,944 \\
\hline 0,5 & 294,375 & 147,500 & 1,180 \\
\hline 0,6 & 294,375 & 177.000 & 1,416 \\
\hline
\end{tabular}

Before grouting, grease is painted on the mould wall for convenient mould stripping. 2 hours are given for the hardening of the material. Then the mold is stripped and 
the material is weighted. The bender elements samples of polymer grouting materials are shown in Fig. 5.
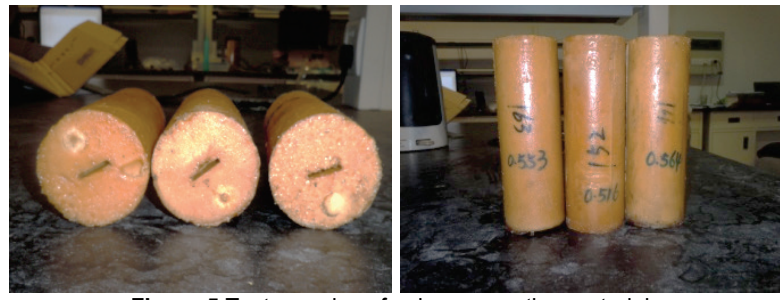

Figure $\mathbf{5}$ Test samples of polymer grouting materials

\section{TEST PROCEDURE}

The samples are divided into several groups according to the density. During the test, actuator and sensor (Fig. 6(a)) are inserted into the end of the two slots. After connecting the equipment (Fig. 6(b)), the function generator (Fig. 6(c)) is then set to generate pulse which is amplified by amplifier and output electric signal transmits to the end of actuator. Then the signal travels in the polymer materials and the signal is received by the sensor and further amplified by amplifier. The transmitting and receiving signal with the same time scale are shown on the oscilloscope (Fig. 6(d)). Then the transmitting time is read and the dynamic shear modulus is calculated by the Eq. (1) and (2).

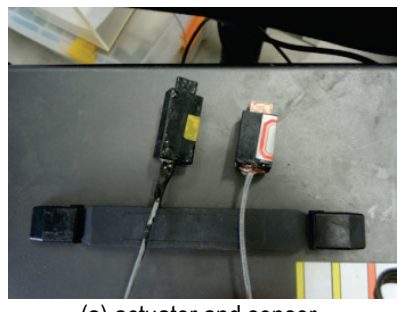

(a) actuator and sensor

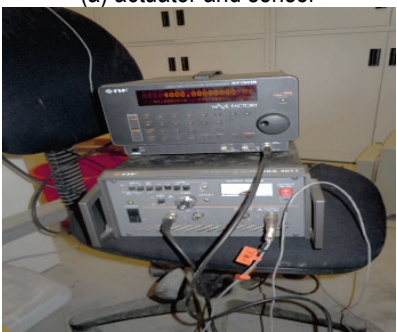

(c) function generator

Figure 6 The test procedure of piezoceramic bender elements

\section{PRECISE MEASUREMENT OF SHEAR MODULUS OF POLYMER GROUTING MATERIALS}

This paper is the first to use the piezoceramic bender elements to test the shear modulus of the polymer grouting materials. As the polymer grouting materials is a new kind of impermeable and reinforced materials for infrastructure engineering, there is no report or specification about its dynamic property. Therefore, how to precisely measure the transmitting time of the shear wave into the polymer materials is the key of the research. The following four factors should be considered to assure the precision.

\subsection{System Delay}

Equipment precision, system error, relaxation time of input and output voltage, and other factors will cause system delay. To precisely measure the velocity of shear wave in polymer grouting materials and get initial value of transmitting time, the system delay should be determined and compensated. The determination and compensation method is as follows: set the distance between the actuator and sensor as zero by connecting the ports record and calculate the difference of the take-off time and the receiving time of the signal (Fig. 7) as the system delay. The system delay of this bender elements system is $24 \mu \mathrm{s}$ which will be deducted in the test.

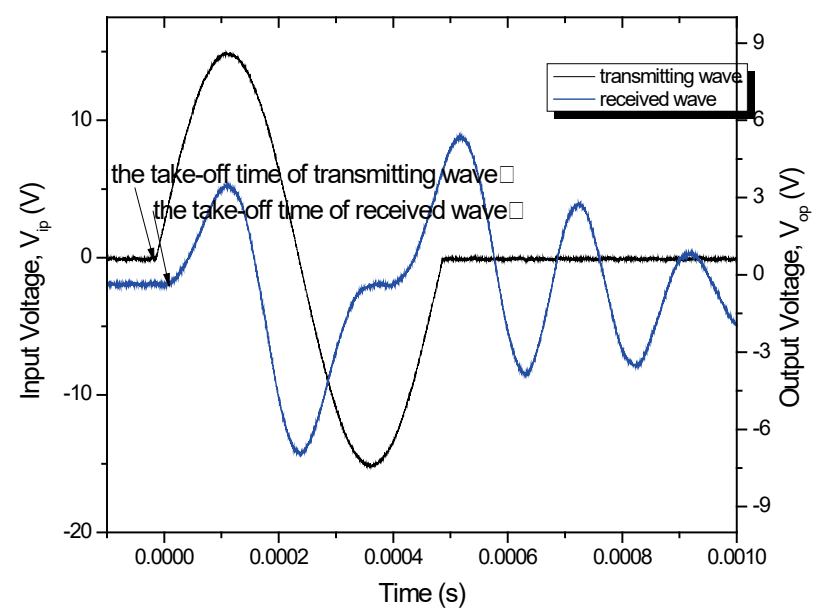

Figure 7 The determination of the system delay

\subsection{Excitation Signal}

Elastic wave includes shear wave and compression wave. The research [8] shows the coupling of the two signals causes near-field-effects and overshooting phenomenon, which is obvious for square wave. For monocycle sine wave, near-field-effects and overshooting phenomenon can be eliminated by choosing suitable excitation frequency. Therefore, monocycle sine wave is selected for this test, shown in Fig. 8.

\subsection{The Selection of the Excitation Frequency for the Bender Elements System}

There are no former reports about the application of the bender elements system in the polymer grouting materials as reference. Therefore, it is necessary to test the excitation frequency. The density with $0.13,0.37$ and 0.51 $\mathrm{g} / \mathrm{cm}^{3}$ of polymer materials is tested respectively, using the excitation frequency of $0.5 k, 1 k, 1.5 k, 2 k, 3 k, 5 k, 8 k, 10 k$ and $15 k$. The results are shown in Fig. 9. It can be seen from the figure, the shear wave velocity varied intensely from $0.5 k$ to $2 k$, while the velocity changes gently from $3 k$ to $15 k$. It is showed the frequency of the shear wave velocity in the polymer grouting materials disperses during the low frequency section while the frequency dispersion is not obvious during the middle and high excitation frequency section. Therefore, middle or high frequency is selected. Considering the feasibility of the experiment, the output frequency is set as $5 k, 8 k$ and $10 k$. 


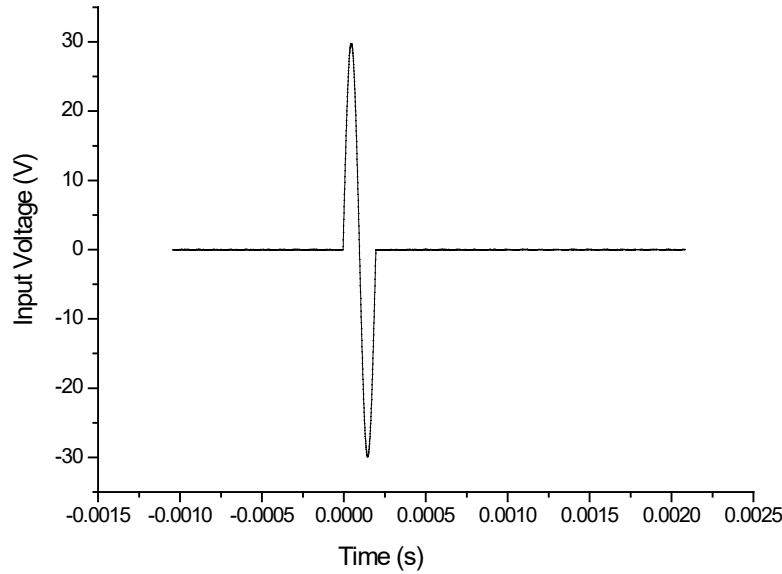

Figure 8 The excitation signal of monocycle sine wave

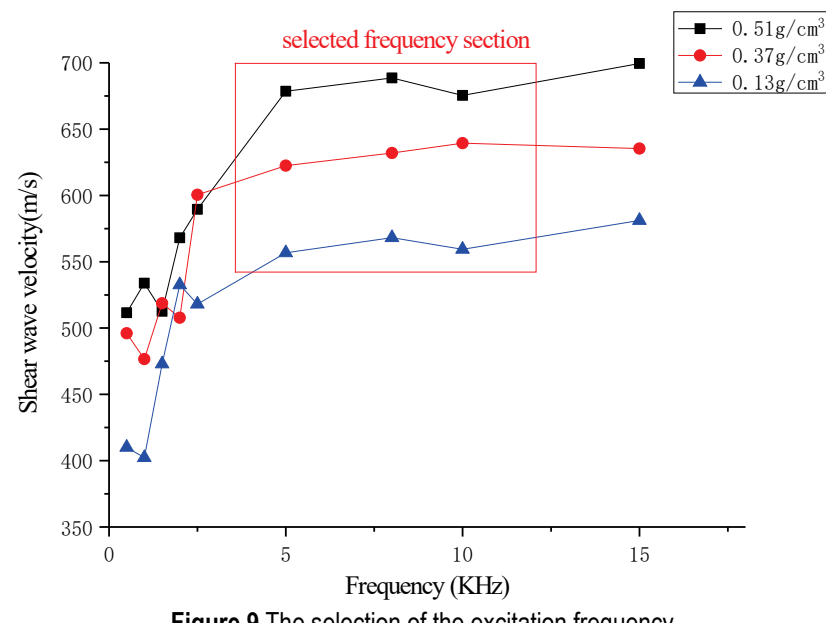

Figure 9 The selection of the excitation frequency

\subsection{The Determined Method for Transmitting Time of Shear Wave of the Polymer Grouting Materials}

The determined methods for transmitting time of shear wave are divided into the time domain method and frequency domain method. The representative time domain method is initially arrival wave of time domain method, which is proposed by Lee [9], Leong [10] and Chen Yunmin [7]. Besides time domain analysis, frequency domain analysis has achieved great progress in recent years, which provides new view for determining the transmitting time of the shear wave. However the time domain method is more mature. So this test selects initially arrival wave of time domain method to measure the transmitting time of shear wave of the polymer grouting materials.

Take polymer grouting materials with the density of $0.3 \mathrm{~g} / \mathrm{cm}^{3}$ under $5 k \mathrm{~Hz}$ frequency as example. The determination method is as follows. The incident wave and received wave with the same time scale are shown in Figure 10. The take-off time of the incident wave $\mathrm{CH} 1$ is the excitation time while the first take-off time of the received time is not the actual arrival time of the sine wave. It is the distortion time caused by reflection and refraction of the shear wave. The second take-off time is the actual arrival time and the time difference is the transmitting time for shear wave velocity.

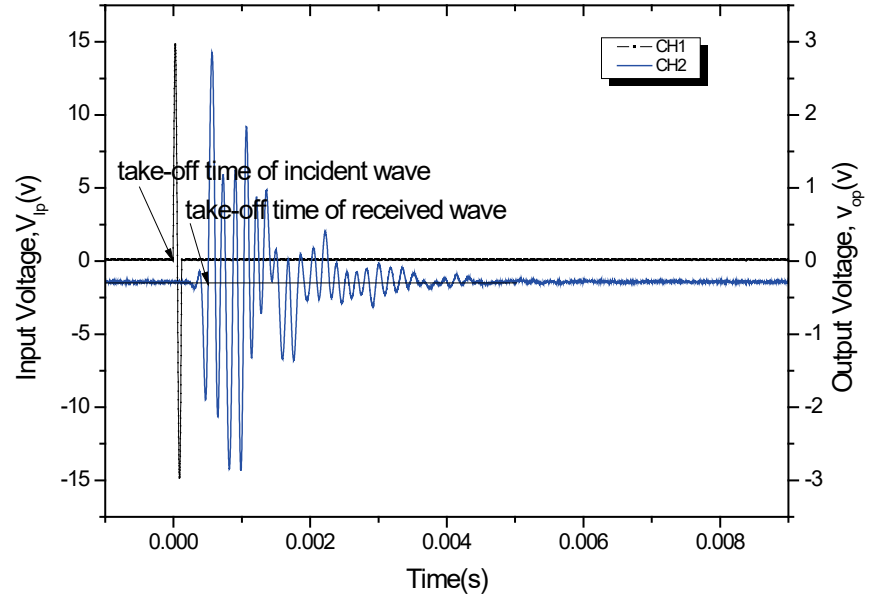

Figure 10 The shear wave under $5 k\left(0.3 \mathrm{~g} / \mathrm{cm}^{3}\right)$

\section{RESULTS ANALYSIS}

Get rid of the outliers, arrange the results and average the shear modulus of the polymer grouting materials under the three frequencies. Typical oscillograph is shown in Fig. 11 (taking the density of $0.339 \mathrm{~g} / \mathrm{cm}^{3}$ for example). Tab. 3 shows the dynamic shear wave velocity and modulus of the polymer grouting materials.
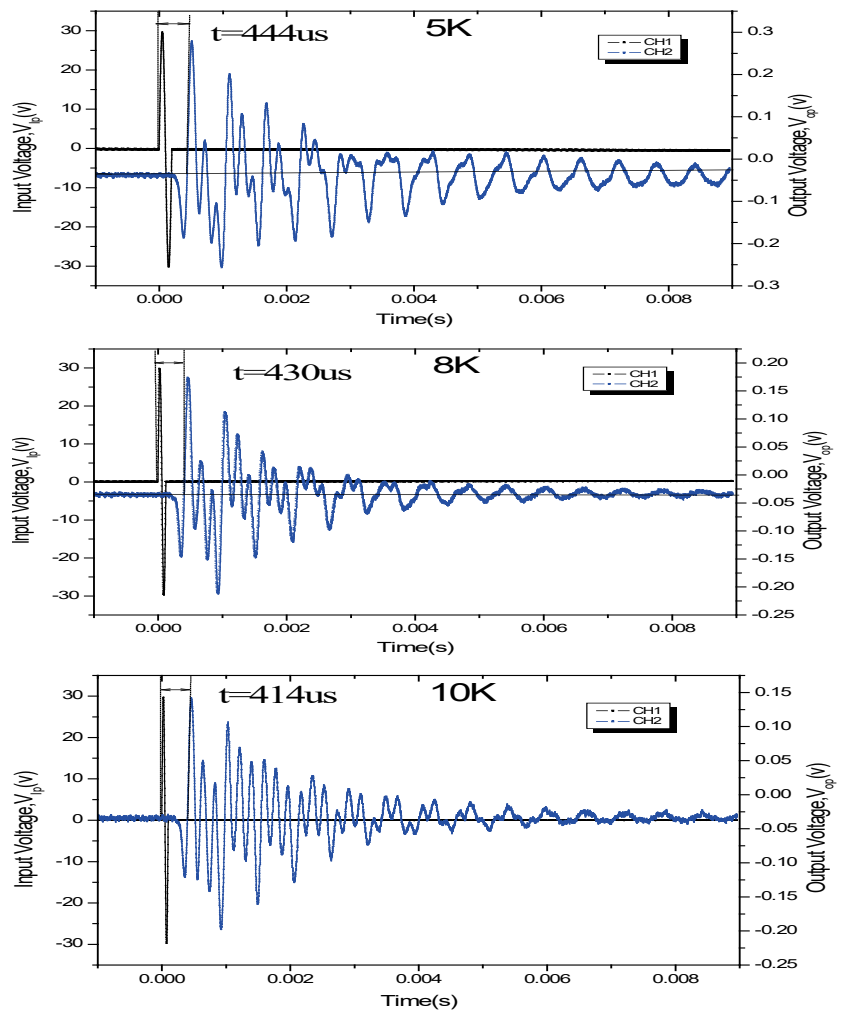

Figure 11 Typical oscillograph of the bender elements test $\left(0.339 \mathrm{~g} / \mathrm{cm}^{3}\right)$

Table 3 Dynamic shear modulus of polymer grouting materials with different density

\begin{tabular}{|c|c|c|}
\hline Density $\left(\mathrm{g} / \mathrm{cm}^{3}\right)$ & $\begin{array}{c}\text { Average shear } \\
\text { wave velocity }(\mathrm{m} / \mathrm{s})\end{array}$ & $\begin{array}{c}\text { Dynamic shear } \\
\text { modulus }(\mathrm{MPa})\end{array}$ \\
\hline 0,129 & 296,312 & 11,326 \\
\hline 0,149 & 290,336 & 12,560 \\
\hline 0,153 & 302,002 & 13,954 \\
\hline 0,156 & 303,654 & 14,384 \\
\hline 0,165 & 315,693 & 16,444 \\
\hline 0,169 & 301,817 & 15,394 \\
\hline
\end{tabular}


Table 3 Dynamic shear modulus of polymer grouting materials with different density (continuation)

\begin{tabular}{|c|c|c|}
\hline Density $\left(\mathrm{g} / \mathrm{cm}^{3}\right)$ & $\begin{array}{c}\text { Average shear } \\
\text { wave velocity }(\mathrm{m} / \mathrm{s})\end{array}$ & $\begin{array}{c}\text { Dynamic shear } \\
\text { modulus }(\mathrm{MPa})\end{array}$ \\
\hline 0,183 & 324,276 & 19.243 \\
\hline 0,227 & 334,419 & 25,386 \\
\hline 0,249 & 352,216 & 30,889 \\
\hline 0,298 & 377,267 & 42,414 \\
\hline 0,299 & 379,769 & 43,123 \\
\hline 0,300 & 398,083 & 47,541 \\
\hline 0,323 & 395,533 & 50,532 \\
\hline 0,329 & 374,388 & 46,114 \\
\hline 0,339 & 378,177 & 48,483 \\
\hline 0,370 & 386,384 & 55,238 \\
\hline 0,401 & 426,574 & 72,968 \\
\hline 0,414 & 406,473 & 68,401 \\
\hline 0,442 & 427,463 & 80,764 \\
\hline 0,499 & 430,766 & 92,594 \\
\hline 0,516 & 429,345 & 95.118 \\
\hline 0,553 & 457,875 & 115,936 \\
\hline 0,564 & 451,437 & 114,940 \\
\hline
\end{tabular}

\subsection{The Influence of Density on Dynamic Shear Modulus}

The relation curve of dynamic shear modulus and density is shown in Fig. 12. It can be seen the value of the dynamic shear modulus of the polymer grouting materials changes from 11.326 to $114.940 \mathrm{MPa}$ with the density changing from 0.129 to $0.564 \mathrm{~g} / \mathrm{cm}^{3}$. With the increase of the density of the polymer grouting materials, both the dynamic shear modulus and the integral rigidity of materials increases. Trend line is added in Fig. 12 and its correlation coefficient $R^{2}=0.99$. It can be seen $G_{\max }$ and pare approximate linear dependent (shown in Eq. (3)).

$G_{\max }=k \rho-a$

where: $k$ - the coefficient of shear modulus $\left(\mathrm{MPa} \cdot \mathrm{cm}^{3} / \mathrm{g}\right)$; $\rho$ - materials density $\left(\mathrm{g} / \mathrm{cm}^{3}\right) ; a$ - modulus constant $(\mathrm{MPa})$.

In the test, the value of $\mathrm{k}$ is 230.146 and a is 22.662 . Eq. (3) has great significance for quickly deciding the dynamic shear modulus of polymer anti-seepage wall in the practical engineering project.

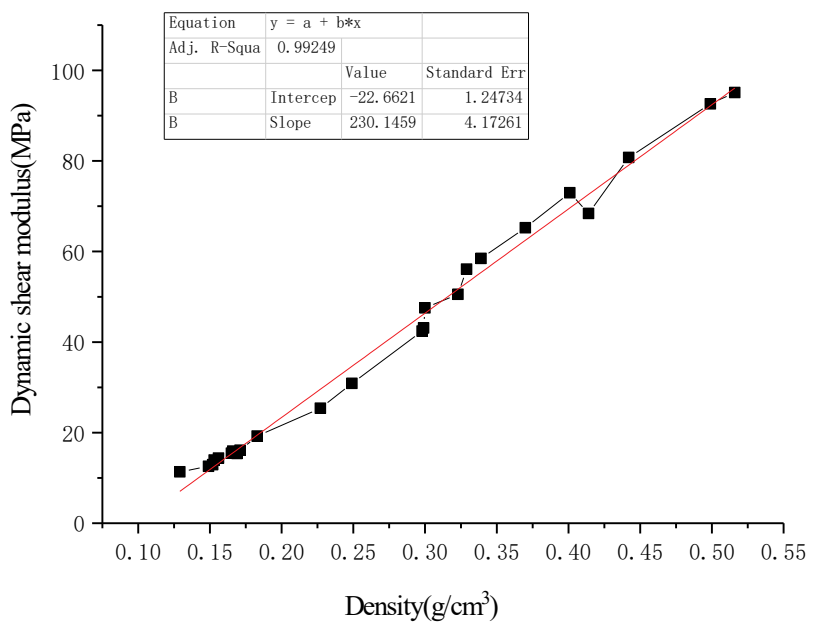

Figure 12 The relationship between dynamic shear modulus and density of polymer grouting materials

\subsection{The Influence of Excitation Frequency on Dynamic Shear Wave Velocity}

The change of the dynamic shear wave velocity under $5 k, 8 k$ and $10 k \mathrm{~Hz}$ with different density is shown in Figure 13. It can be seen from Fig. 13 the changing trend of the dynamic shear wave velocity with density under the three frequencies is consistent. However, in the middle and high frequency section, the higher the frequency, the greater the shear wave velocity.

This result can be explained from the following two aspects. First, according to the energy consumption characteristic of high polymer [11] (Fig. 14), when the excitation frequency is in the middle frequency section, the chain segment cannot keep up with the external forces and the internal consumption first rises and then falls under certain frequency. The excitation frequency selected in the test should be within the descending section (CD section), that is, the higher the frequency, the smaller the mechanical relaxation behaviour (internal friction) of polymer materials and the faster the transmitting velocity. Second, decreasing the frequency increases the near-field effect which makes the front end of the shear wave pulled down (Fig. 15) and finally results in the propagation time increased and the shear wave velocity decreased.

It should be noted, although frequency changes will cause changes for the shear wave velocity of polymer grouting materials, from the frequency test in Section 5.3, it can be seen that the dispersion of polymer grouting material is not significant under medium and high frequency excitation pulses, and the dynamic shear modulus of the polymer grouting material used in the middle and high frequency test is feasible.

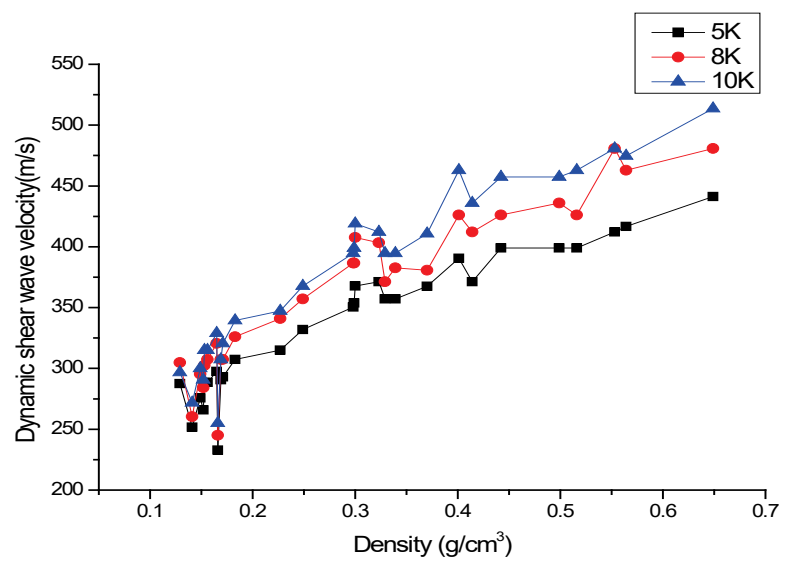

Figure 13 The influence of impulse frequency on dynamic shear modulus

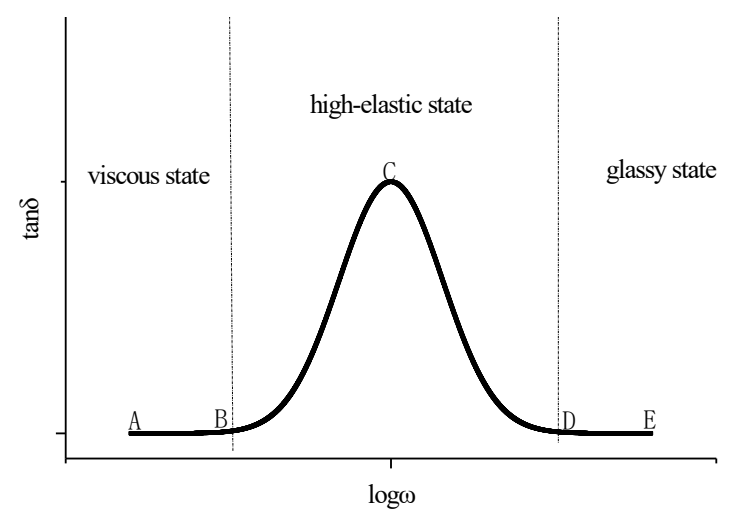

Figure 14 The relationship between internal friction and frequency of polymer 


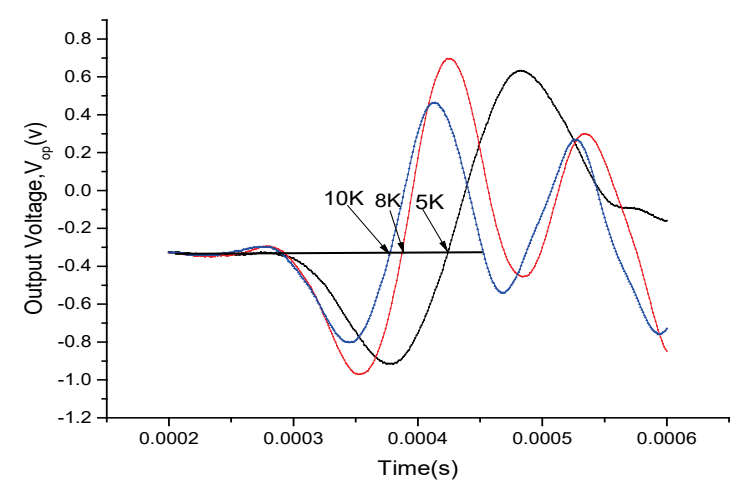

Figure 15 The relationship between impulse frequency and near-field effect

\subsection{The contrast of dynamic and static elastic modulus}

Based on the theory of materials mechanics, the following can be got:

$$
E_{\max }=G_{\max } \cdot 2(1+\mu)
$$

where: $E_{\max }-$ dynamic elastic modulus $(\mathrm{MPa}) ; \mu-$ dynamic Poisson ration.

The dynamic elastic modulus can be calculated by the dynamic shear modulus with Eq. (4). The static elastic modulus of the polymer grouting materials is studied in [12] and [13]. Ref. [12] researches the static elastic modulus of polymer cylinder with the size of $\varnothing 40 \times 40 \mathrm{~mm}$ (Static elastic modulus (1) in Fig. 16) and $\varnothing 40 \times 80 \mathrm{~mm}$ (Static elastic modulus (2) in Fig. 16) by unconfined compressive strength test. However, the research only investigates the low density section $\left(0-0.25 \mathrm{~g} / \mathrm{cm}^{3}\right)$. Ref. [13] studies the static elastic modulus of polymer cylinder with the size of $\varnothing 150 \times 300 \mathrm{~mm}$ (Static elastic modulus (3) in Fig. 16) by unconfined compressive strength test and the density section covers the low, middle and high density section (0$0.78 \mathrm{~g} / \mathrm{cm}^{3}$ ). The dynamic elastic modulus calculated by Eq. (4) and the static elastic modulus from the [12] and [13] are shown in Fig. 16.

It can be seen in Fig. 16 the numerical value difference of the dynamic and static modulus is not obvious. The dynamic elastic modulus by the bender elements test is stable and regular while the static elastic modulus from the [12] and [13] is significantly different. Wild change and leap during the high density section occur in the data in the literature 13, which can be explained as the difference of the test methods and energy absorption property of polymer materials. Kurauchi [14] points out that the energy absorption of polyfoam is similar to that of the ductile materials. Compression proceeds layer by layer. So that mechanism allows the repeated absorption of energy, which causes high energy absorption and the phenomenon is very obvious on the fragile polyfoam. Compression test is used to obtain the static elastic modulus in [12] and [13]. In [12] and [13], the materials are with high energy absorption property. Besides, the polymer materials are fragile in high density range $\left(0.4-0.8 \mathrm{~g} / \mathrm{cm}^{3}\right)$, which can explain the wild change and leap during the high density section.

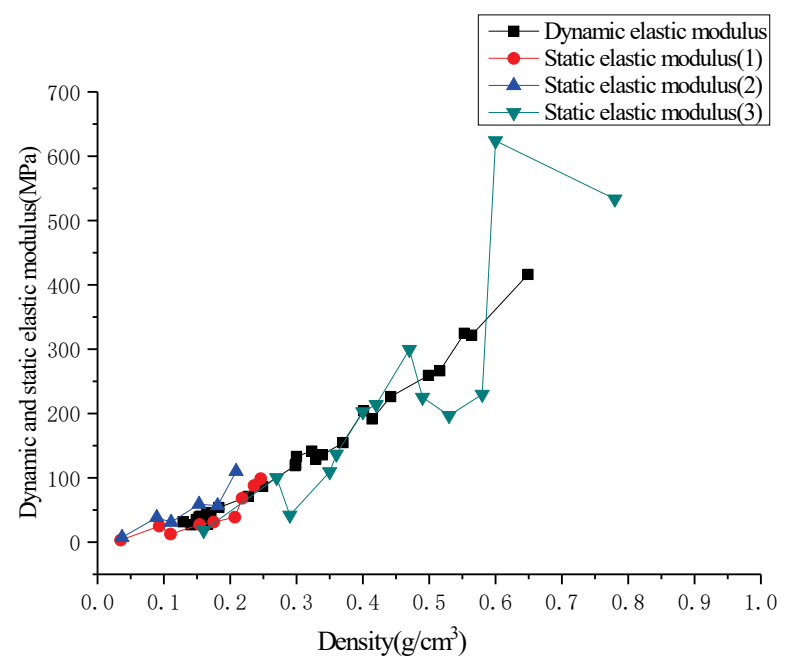

Figure 16 The comparison between dynamic elastic modulus and static elastic modulus

The data from Fig. 16 are fitted with the least square method and the quadratic polynomial function of dynamic and static elastic modulus is obtained, which is shown in Fig. 17.

The relation is:

$E_{\mathrm{d}}=42.411+0.829 E_{\mathrm{s}}-\left(4.033 \times 10^{-4}\right) E_{\mathrm{s}}^{2}$

where: $E_{\mathrm{d}}-$ dynamic elastic modulus $(\mathrm{MPa}) ; E_{\mathrm{s}}-$ static elastic modulus (MPa).

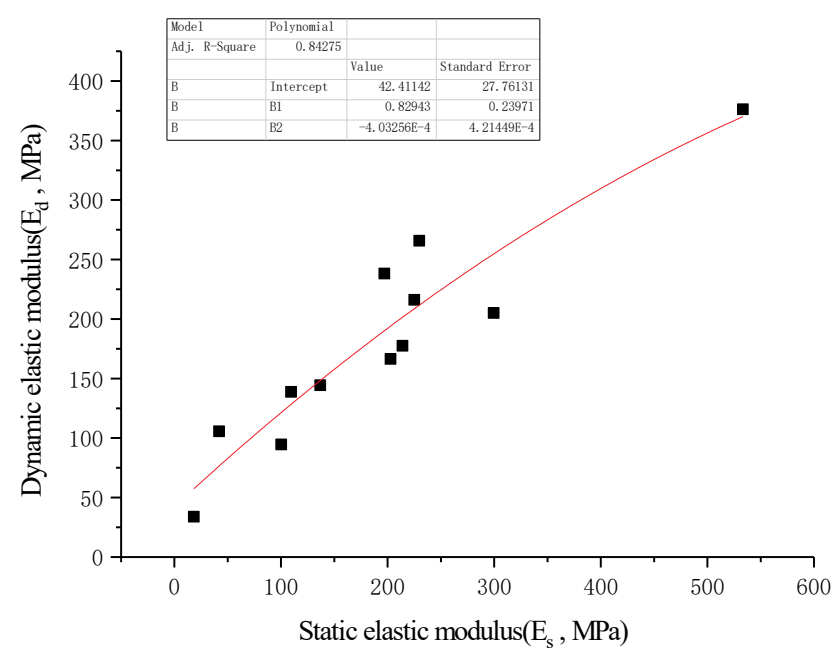

Figure 17 The relationship between dynamic elastic modulus and static elastic modulus

\subsection{The Contrast of Dynamic Shear Modulus of Polymer Grouting Materials and Silty Clay}

To research the rigidity of soil, the shear wave velocity of silty clay which is widely used in dam construction in Henan province is tested by the bender elements system. The test procedure includes: making soil sample with the same compactness as that of the earth-rock dam, making slots in the material, placing actuator and sensor into the slots (Fig. 18(a)), and casting Ottawa sand to fix transducers (Fig. 18(b)). Since natural silty clay usually has characteristic frequency, the dispersivity of shear wave velocity is not considered. In the test, the monocycle sine 
wave and the excitation frequency of $2 k, 3 k$ and $4 k$ are selected. The results are shown in Tab. 4.

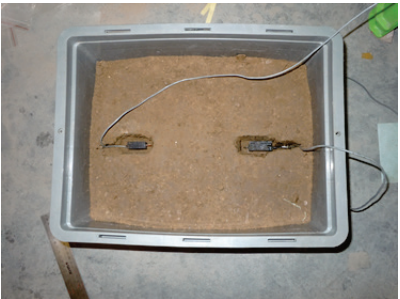

(a) putting actuator and sensor

Figure 18 Testing silty clay using piezoceramic bender elements

Table 4 Testing results of silty clay

\begin{tabular}{|c|c|c|c|c|}
\hline \multicolumn{5}{|c}{ Table 4 Testing results of silty clay } \\
\hline $\begin{array}{c}\text { Density } \\
\left(\mathrm{g} / \mathrm{cm}^{3}\right)\end{array}$ & Frequency & $\begin{array}{c}\text { Transmitting } \\
\text { time }(\mu \mathrm{s})\end{array}$ & $\begin{array}{c}\text { System delay } \\
(\mu \mathrm{s})\end{array}$ & $\begin{array}{c}\text { Shear wave } \\
\text { velocity } \\
(\mathrm{m} / \mathrm{s})\end{array}$ \\
\hline \multirow{3}{*}{1.92} & $2 k$ & 1270 & 24 & 120,391 \\
\cline { 2 - 5 } & $3 k$ & 1220 & 24 & 125,422 \\
\cline { 2 - 5 } & $4 k$ & 1190 & 24 & 128,652 \\
\hline
\end{tabular}

The dynamic shear modulus of silty clay is calculated to be $29.91 \mathrm{MPa}$. The common density of the polymer grouting materials is $0.1-0.3 \mathrm{~g} / \mathrm{cm}^{3}$ and their dynamic shear modulus is $11-47 \mathrm{MPa}$. It is obvious the two have the similar dynamic modulus. It can be expected for the dam and the wall to have consistent deformation under seismic loads.

\section{CONCLUSIONS}

(1) This paper is the first to apply piezoceramic bender elements system to test small-strain maximum shear modulus $G_{\max }$ of polymer grouting materials. The bender element test system has many advantages including clear principle, easy operation, damage-free and massive repeated test characteristics, which provides a new laboratory measuring method for dynamic shear modulus of the polymer grouting materials.

(2) To assure the measurement precision of the shear wave velocity of polymer grouting materials, the system delay should be determined and compensated. The monocycle sine wave is selected to eliminate the nearfield-effects and the overshooting phenomenon. It is better to select the middle and high excitation frequency for bender elements test since the dispersivity of shear wave velocity can be weakened. Different from former studies, the initially arrival wave of time domain method is used to decide the transmit time and data with good coherence are obtained.

(3) With the increase of the density of the polymer grouting materials, both the dynamic shear modulus and the integral rigidity of materials increase and the integral rigidity of materials increases. Moreover, the density and dynamic shear modulus are approximate linearly dependent. The shear wave velocity increases with the increase of the excitation frequency under the same density. Polynomial fitting is performed using the least square method and the quadratic polynomial function of dynamic and static elastic modulus is obtained. The dynamic property of the polymer grouting materials obtained from the test provides basic theoretical reference and reference for dynamic response analysis and engineering application.
(4) The dynamic shear modulus of polymer grouting materials and typical dam construction materials are contrasted. Results show that these two materials have similar dynamic modulus and that the dam and the wall have the compatible deformation under seismic loads is expected.

\section{Acknowledgements}

This paper is supported by the Basic and Frontier Technology Research Program of Henan Province (52110611) and Key Scientific Research Program of Higher Education of Henan Province (18A570002).

\section{REFERENCES}

[1] Shirley, D. J. \& Hampton, L. D. (1978). Shear-wave Measurements in Laboratory Sediments. The Journal of the Acoustical Society of America, 63(2), 607-613. https://doi.org/10.1121/1.381760

[2] Ji, M. X. (2005). Study on the Shear Wave Velocity Measurement from Bender Elements and Dynamic Properties of Saturated Soft Marine Clay. Doctoral Dissertation, Zhejiang University, Hangzhou, China.

[3] Wu, H. W., Li, Q., \& Liu, G. B. (2013). Measurements of Small-Strain Inherent Stiffness Anisotropy of Intact Shanghai Soft Clay Using Bender Elements. Chinese Journal of Geotechnical Engineering, 35(1), 150-156.

[4] Zhou, Y. G. (2007). Shear Wave Velocity Based Characterization of Soil Structure and Its Effects on Dynamic Behavior. Doctoral Dissertation, Zhejiang University, Hangzhou, China.

[5] Gu, X. Q., Yang, J., Huang, M. S., \& Gao, G. Y. (2016).Combined Bender Element, Resonant Column and Cyclic Torsional Shear Tests to Determine the Small Strain Shear Modulus of Sand. Chinese Journal of Geotechnical Engineering, 38(4), 740-746.

[6] Bai, L. D., Xiang W., Savidis, A. S., \& Rackwitz, F. (2012). Resonant Column and Bender Element Tests on Maximum Shear Modulus of Dry Sand. Chinese Journal of Geotechnical Engineering, 34(1), 184-188.

[7] Chen, Y. M., Zhou, Y. G., \& Huang, B. (2006). International Parallel Test on the Measurement of Shear Modulus of Sand Using Bender Elements. Chinese Journal of Geotechnical Engineering, 28(7), 874-880.

[8] Ji M. X., Chen Y. M., \& Huang. B. (2003). Method for Precisely Determining Shear Wave Velocity of Soil from Bender Element Tests. Chinese Journal of Geotechnical Engineering, 25(6), 732-736.

[9] Lee, J. S. \& Santamarina, J. C. (2005). Bender elements: Performance and signal interpretation. Journal of Geotechnical and Geoenvironmental Engineering, 131(9), 1063-1070. https://doi.org/10.1061/(ASCE)1090-0241(2005)131:9(1063)

[10] Leong, E. C., Yeo, S. H., \& Rahardjo, H. (2005). Measuring shear wave velocity using bender elements. Geotechnical Testing Journal, 28(5), 488-498. https://doi.org/10.1520/GTJ12196

[11] He, M. J., Chen, W. X., \& Dong X. X. (2000). Polymer Physics. Shanghai: Fudan University Press.

[12] Liu Zhiyuan. (2007). The Experimental Study on Engineering Property of Polymer Grouting Materials. Master's Thesis, Zhengzhou University, Zhengzhou, China.

[13] Liu Yong. (2009). The Experimental Study on polyurethane and Its Concrete. Master's Thesis, Zhengzhou University, Zhengzhou, China. 
[14] Kurauchi T. J. \& Ohta, T. (1984). Energy Absorption in Blends of Polycarbonate with ABS and SAN. Material Science, 19(5).1699-1709. https://doi.org/10.1007/BF00563068

\section{Contact information:}

Jia LI, PhD

Zhengzhou University,

Wenhua Road 97\#, Zhengzhou, Henan, 450002, China

E-mail: lijia@zzu.edu.cn

Bo WANG, PhD, Professor

Zhengzhou University,

Wenhua Road 97\#, Zhengzhou, Henan, 450002, China

E-mail: wangbo@zzu.edu.cn

Jingwei ZHANG, PhD, Senior Enginee

(Corresponding author)

Zhengzhou University,

Wenhua Road 97\#, Zhengzhou, Henan, 450002, China

E-mail: zhangjw1998@163.com 